\title{
Onchological review to pet medicine
}

\author{
Bulent Elitok* \\ Afyon Kocatepe University, Faculty of Veterinary Medicine, Department of Internal Medicine, 03200/Afyonkarahisar-Turkey
}

\begin{abstract}
Cancer is most commonly seen, caused to deaths and resistable diseases of the dogs and cats as well as humans. Pets today have a better chance of being successfully treatment chooices for all the cancer types, if it can be early diagnosed. The aim of this review is believed to give information about cancer incidence of the dogs and cats along with commonly using treatments in practice.
\end{abstract}

\section{Introduction}

Cancer is a dangerous disease, and commonly seen in the pets as well as human kinds. Naturally occurring tumors related to cancer in dogs reported that develop twice as frequently as in man, have histopathologic features and a biologic behavior similar to tumors in man, and progress at a more rapid rate than in man [1-3]. An estimated 6 million dogs and nearly 6 million cats will be diagnosed with cancer this year. According to The Veterinary Cancer Society, cancer is the leading cause of death in $47 \%$ of dogs, especially dogs over age ten, and $32 \%$ of cats. Dogs get cancer at about the same rate as humans, while cats get fewer cancers. Approximately 1 in 4 dogs will, at some stage in their life, develop neoplasia. Almost half of dogs over the age of 10 will develop cancer [3-5].

Most common signs of neoplasia in pets are abdominal swelling, bleeding from the mouth, nose or other body openings, difficulty breathing, difficulty eating, lumps, bumps or discolored skin, nonhealing wounds, persistent diarrhea or vomiting, sudden changes in weight, unexplained swelling, heat, pain or lameness, visible mass/ tumor $[3,6]$.

Some viruses, genetic components, exposure to carcinogens, and other unknown factors are effective in cancer formation [3]. The relatively high incidence of some cancers, similar biologic behavior, large body size, comparable responses to cytotoxic agents, and shorter overall lifespan are the factors that contribute to the advantages of the companion animal model [7].

There are more than 100 different types of cancer that can be grouped into one of six major categories:

Sarcomas: Cancer that begins in tissue that connects, supports or surrounds other tissues and organs (such as muscle, bone and fibrous tissue).

Carcinomas: Cancer cells that originate in tissues that cover a body surface, line a body cavity or make up an organ.

Lymphomas: Cancer that occurs in cells that make up an important component of the immune system and protect the body's cells.

Leukaemias: Cancer that occurs in the blood-forming tissues and blood cells.
Skin cancers: Cancer that originates in the skin cells; the most common in dogs being mast cell tumour.

Brain tumours: Cancer that originates in the brain cells [4].

The canine malignancies that are of practical use for comparative therapeutic studies include lymphoma, mammary tumors, oral melanoma, lung tumors, nasal tumors, soft tissue sarcomas, and osteosarcoma [1]. Malignant melanoma, squamous cell carcinoma, fibrosarcoma, osteosarcoma, and acanthomatous epulis are mostly seen in dogs as orofacial tumors, while oral tumor of cats is squamous cell carcinoma [8].

The most common tumors that affect the musculoskeletal system in cats are injection site sarcomas. These can be categorized as either primary or metastatic within the bony or soft structures that comprise the musculoskeletal system in dogs and cats. Clearly, the most common tumor that affects the musculoskeletal system in dogs is osteosarcoma. These tumors are locally infiltrative; whereas up to $25 \%$ metastasize, most animals die from our inability to control local disease [9].

Canine and feline malignant mammary tumors are fairly common in middle-aged animals and have a metastatic pattern similar to that in women; that is, primarily to regional lymph nodes and lungs [10]. The thoracic cavity contains numerous tissue types from which tumors may arise. Broadly speaking, the cavity is comprised of the pleural surfaces, the mediastinum and its enclosed viscera, and the lungs [11].

The treatment of cancer has evolved over the last few decades to parallel treatment in humans. The goal of veterinary cancer therapy is to achieve a "complete clinical remission" or to make the pet as normal as possible with no outward evidence of cancer [4]. It should remember that each type of neoplasia requires individual care. Treatment may include one or a combination of therapies such as surgery, chemotherapy, radiation, cryosurgery (freezing), hyperthermia (heating) or immunotherapy $[3,5,12]$.

${ }^{*}$ Correspondence to: Bulent Elitok, Afyon Kocatepe University, Faculty of Veterinary Medicine, Department of Internal Medicine, 03200/AfyonkarahisarTurkey, E-mail: elitok1969@hotmail.com

Key words: Pet, cancer, therapy

Received: March 21, 2018; Accepted: April 14, 2018; Published: April 17, 2018 
Chemotherapy is an important and effective modality of modern cancer treatment [13]. Oral tumors, especially melanomas, are the most common canine malignant tumor in the oral cavityand metastasis is frequently seen. The response to chemotherapy and radiation might be disappointed [10]. Squamous cell carcinomas, especially in the gum, are excellent models for radiation therapy studies. However, Elitok et al. [14], reported that some drugs such as tetracycline was very effective on treatment of squamous cell carcinoma of the skin in dogs.

The most frequently irradiated tumors were soft tissue sarcomas in dogs, and oral squamous cell carcinoma in cats [15]. Nasal carcinomas, tend to metastasize slowly, are commonly treated with radiation therapy. Primary lung tumors and soft tissue sarcomas are excellent models for studying combined modality therapy such as surgery with chemotherapy or biological response modifiers [10].

Chemotherapy is indicated in neoplastic disease characterised by early metastasis and/or local invasive growth. The results of chemotherapy in dogs and cats are so far moderate [16]. Therefore, the benefits of pharmacokinetics can be considered from two points of view, the impact on the average patient and that on the individual patient. For the average patient, pharmacokinetic studies answer basic questions about dose, schedule, and route of administration. For the individual patient, benefits are derived from the ability of pharmacokinetic studies to define parameters of toxicity and suggest possible dose modifications [17].

Although reports describing anticancer chemotherapy use in dogs and cats for tumors of the thoracic cavity largely have been anecdotal, as advances are made in the chemotherapeutic management of comparable tumors in human cancer patients and as veterinarians become familiar with these compounds, use of antineoplastics as an adjunct to, or in place of, local treatment modalities should increase [11].

Surgical excision is the preferred treatment for tumors, but is often more beneficial when combined with chemotherapy, radiotherapy or immunotherapy. The successful diagnosis and management of neoplastic disease in domestic animals necessitates a thorough awareness of the clinical presentation and biologic behavior of specific tumors on the part of veterinarians who provide health care for these species [18].

Surgical treatment offers the greatest chance of cure, although several options are available for early, less invasive lesions [19]. Oral tumors of the cats ara highly invasive tumors that occasionally can be effectively treated with surgery alone, but that often requires a combination of surgery and radiation therapy. Bone involvement tumors is common in pets, and complete excision often requires partial mandibulectomy or partial maxillectomy. Survival times after surgery are most strongly influenced by tumor type (or metastatic rate) and tumor location [8]. Canine osteosarcoma is a malignant aggressive bone tumor with a $90 \%$ metastasis rate after surgical amputation. Its predictable metastatic rate and pattern and its relative resistance to chemotherapy make this tumor particularly attractive for studying anti-metastasis approaches [10].

Neoplasia is frequently treatable, if it can be early diagnosed. With the increase in new therapeutic agents (traditional chemotherapy, gene therapy, biologic agents, etc.), combined them in the therapy may increase the success of ttreatment and usefull for detecting of efficacy and toxicity of them [7]. The most important is the basis of the One Health initiative, supporting the idea of collaboration between human and animal health researchers and clinicians to study spontaneous disease processes and treatment in animals to inform human health [5].

\section{References}

1. Hahn KA, Bravo L, Adams WH, Frazier DL(1994) Naturally occurring tumors in dogs as comparative models for cancer therapy research. In Vivo 8: 133-143. [Crossref]

2. http://www.fetchacure.org/resource-library/facts.

3. https://www.avma.org/public/PetCare/Pages/Cancer-in-Pets.aspx.

4. https://www.vetoncologyconsults.com/content/cancer-pets.

5. Gustafson DL, Duval DL, Regan DP, Thamm DH (2018) Canine sarcomas as a surrogate for the human disease. Pharmacol Ther S0163-7258: 30019-26. [Crossref]

6. Cannon CM (2015) Cats, Cancer and Comparative Oncology Vet Sci 2: 111-126 [Crossref]

7. Vail DM, MacEwen EG (2000) Spontaneously occurring tumors of companion animals as models for human cancer. Cancer Invest 18: 781-792. [Crossref]

8. Berg J (1998) Principles of oncologic orofacial surgery. Clin Tech Small Anim Pract 13: 38-41. [Crossref]

9. Chun R (2005) Common malignant musculoskeletal neoplasms of dogs and cats. Vet Clin North Am Small Anim Pract 35: 1155-1167. [Crossref]

10. MacEwen EG (1990) Spontaneous tumors in dogs and cats: models for the study of cancer biology and treatment. Cancer Metastasis Rev 9: 125-136. [Crossref]

11. Moore AS (1992) Chemotherapy for intrathoracic cancer in dogs and cats. Probl Vet Med 4: 351-64. [Crossref]

12. Turrel JM, Theon AP (1988) Reirradiation of tumors in cats and dogs. J Am Vet Med Assoc 193: 465-469. [Crossref]

13. Helfand SC (1990) Clinical management of the cancer patient. Principles and applications of chemotherapy. Vet Clin North Am Small Anim Pract 20: 987-1013. [Crossref]

14. Elitok OM, Elitok B,Yüksel H (2013) Treatment of naturally occuring squamous cell carcinomas with mixed therapy plus tetracycline in dogs. J Vet Adv Anim 12: 419-422.

15. Farrelly J, McEntee MC (2014) A survey of veterinary radiation facilities in 2010. Vet Radiol Ultrasound 55: 638-643. [Crossref]

16. Austie BA, Rutteman GR, Misdorp W (1988) Chemotherapy of tumors in dogs Tijdschr Diergeneeskd 113: 299-310. [Crossref]

17. Rosenthal RC (1988) The impact of pharmacokinetics on cancer chemotherapy. Vet Clin North Am Small Anim Pract 18: 1133-1139. [Crossref]

18. Cockerell GL, MacCoy DM (1978) Clinicopathological manifestations of selected neoplasms. Cornell Vet 68: 133-150. [Crossref]

19. Thomson M (2007) Squamous cell carcinoma of the nasal planum in cats and dogs. Clin Tech Small Anim Pract 22: 42-45. [Crossref]

Copyright: (C2018 Elitok B. This is an open-access article distributed under the terms of the Creative Commons Attribution License, which permits unrestricted use, distribution, and reproduction in any medium, provided the original author and source are credited. 